\title{
Are "armchair socialists" still sitting? Cross sectional study of political affiliation and physical activity
}

\author{
(c) (1) (8) OPEN ACCESS
}

\author{
Adrian Bauman professor, Joanne Gale research fellow, Karen Milton research fellow
}

Prevention Research Collaboration, School of Public Health, Charles Perkins Centre D17, Level 6 The Hub, University of Sydney, NSW 2006 , Australia

\begin{abstract}
Objective To examine the validity of the concept of left wing "armchair socialists" and whether they sit more and move less than their right wing and centrist counterparts.
\end{abstract}

Design Secondary analysis of Eurobarometer data from 32 European countries.

Setting The study emanated from the authors' sit-stand desks (rather than from their armchairs).

Participants Total of 29193 European adults, of whom 1985 were left wing, 1902 right wing, 17657 political centrists, and 7649 politically uncommitted.

Main outcome measures Self-reported political affiliation, physical activity, and total daily sitting time.

Methods Linear models were used to examine the relation between physical activity, sitting time, and reported political affiliation.

Results The findings refute the existence of an "armchair socialist"; people at the extremes of both ends of the political spectrum were more physically active, with the right wing reporting 62.2 more weekly minutes of physical activity (95\% confidence interval 23.9 to 100.5$)$, and the left wing 57.8 more minutes (20.6 to 95.1 ) than those in the political centre. People with right wing political affiliations reported 12.8 minutes less time sitting a day (3.8 to 21.9) than the centrists. It is those sitting in the middle (politically) that are moving less, and possibly sitting more, both on the fence and elsewhere, making them a defined at-risk group.

Conclusions There is little evidence to support the notion of armchair socialists, as they are more active than the mainstream in the political centre. Encouraging centrists to adopt stronger political views may be an innovative approach to increasing their physical activity, potentially benefiting population health.

\section{Introduction}

The term "armchair socialist" refers to people who are politically left wing but make pronouncements about politics rather than actively helping the cause. The original term was used in the 19th century German School of Economics, where academic social policy advocates were deprecated as "socialists of the chair" (Kathedersozialisten). ${ }^{1}$ The term has evolved from its Germanic roots, especially in the popular media, to now whimsically characterise middle class people who make political pronouncements without engaging in political activism. Current synonyms include "limousine liberal," which is used in the United States, and "chardonnay socialist," "champagne socialist," or "armchair revolutionary," used in the UK and Australia.

The purpose of this research was to test the validity of the "armchair socialist" construct; are self identified left wing political views associated with increased sitting time and decreased physical activity? Given the known health benefits of physical activity ${ }^{2}$ and increasing epidemiological evidence for reducing sitting time, ${ }^{3}$ we hypothesised that if armchair socialists exist, their health could be compromised.

\section{Methods}

The Eurobarometer is a cross national serial survey conducted on behalf of the European Commission. The self report survey is conducted with multistage probability samples of adults (aged $\geq 18$ years) from 32 European countries. More information on the Eurobarometer series can be found at www.gesis.org/en/ eurobarometer/survey-series/standard-special-eb/.

We used data from the Eurobarometer 64.3 survey conducted in $2005 .{ }^{4}$ The data are publicly accessible and available for use, except for commercial purposes. The survey included a question on political affiliation as well as questions from the validated International Physical Activity Questionnaire (IPAQ) ${ }^{5}$ that assessed both physical activity and sitting time across all domains (work, household, transport, leisure). Informed consent was obtained from all those surveyed.

The question on political leaning asked respondents to rate their political orientation from 1 (far left wing) to 10 (far right wing). 
Given recent declines in political extremism, we used the far left wing self categorisation of political affiliation (scores of 1 or 2), under the premise that socialists would now self define only at the extreme left of political orientation. To balance the analysis, we also included far right wingers (scores 9 or 10) to examine whether those at the opposite end of the political spectrum are more active and sit less than those at the extreme left. People with scores of 3-8 were described as politically centrist.

The IPAQ provided data on weekly minutes of vigorous intensity activity, moderate intensity activity, and walking, and these scores were summed to estimate total physical activity. ${ }^{5}$ The IPAQ also includes a validated single item question on total daily minutes of sitting time. ${ }^{6}$

We calculated descriptive statistics to determine the unadjusted proportions of the participants classified into each political affiliation group overall and by country and education level. We then used linear regression models to model the relation between each outcome and political persuasion. The response variables modelled were physical activity (walking, moderate, vigorous, and total) and sitting time. We controlled for potential confounders by adding country, education level, age group, and sex as fixed effects in the model. Political centrists were used as the reference category. A substantial amount of data was missing; almost all missing data were on self classified political orientation, and we therefore included a "missing" category in the model. Analyses were carried out in SAS v9.3.

\section{Results}

We used data from all 32 countries. The mean age of the sample was 46.7 (SD 18.2) years. Of the 29193 respondents, 1985

$(6.8 \%)$ reported political affiliation on the extreme left, 17657 (60.5\%) reported centrists views, and 1902 (6.5\%) right wing affiliation; data were missing for 7649 (26.2\%) respondents. Some countries, such as Italy, Spain, and the former Eastern Germany, showed higher rates of left wing orientation, while the Baltic countries and Turkey showed higher rates of right wing orientation. Among those without tertiary education, 1134 (7.1\%) were left wing and $1086(6.8 \%)$ were right wing; rates were similar among the tertiary educated group, with $651(6.7 \%)$ left wing and $629(6.5 \%)$ right wing.

Table $1 \Downarrow$ shows that people who were left wing reported more vigorous activity each week than centrists (29.6 min, 95\% confidence interval 11.5 to 47.7 ), as did those on the right wing ( $27.7 \mathrm{~min}, 9.1$ to 46.3 ). Those with unknown political affiliation were similar to the centrists. Left and right wingers did not differ on moderate minutes of physical activity from centrists or people with unknown political affiliation, but both politically active extremes reported significantly more minutes of walking than people in the centre. For total physical activity, left wingers reported 57.8 minutes a week $(95 \%$ confidence interval 20.6 to 95.1) and right wingers 62.2 (23.9 to 100.5) minutes more than centrists. Those without reported political affiliation were 40.3 (63.5 to 17.1) minutes less active than those in the centre.

For sitting time, political extremists on the right reported 12.8 (3.8 to 21.9) minutes a day less sitting time than centrists, similar levels to those of unknown political persuasion. People on the left wing did not significantly differ from those in the centre, indicating a lack of evidence that the extreme left sit more, as implied by the term armchair socialist.

\section{Discussion}

Our findings refute the existence of an armchair socialist; both left and right wing ideologues were significantly more physically active, and those on the right spent less time sitting than those in the centre even after we had adjusted for age, sex, education, and country. Busy people at both ends of the political spectrum do not seem to have as much time for idleness. The increased time spent walking and doing vigorous physical activities suggests that they might be out agitating in the field, mobilising the community, and actively distributing ideas and propaganda.

The size of the differences in physical activity—around an hour a week more than the centrists-may be health enhancing for people on the left and right. It is those sitting in the middle (politically) that are truly inactive, and may be sitting more (both on the fence and elsewhere), making them a defined at-risk group. People for whom political affiliation was unknown had even lower rates of physical activity, although they reported sitting less than people in the centre, suggesting either that they are the group most at risk from physical inactivity or that they are in denial when responding to surveys, not reporting any political affiliation and reporting low physical activity levels and low sitting.

\section{Implications}

Centrists and the politically uncommitted may be at greater risk of non-communicable diseases because of their inertia. ${ }^{78}$ This evidence linking political extremism with higher physical activity levels might explain why politics tends to be more extremist in the United States, where politicians "run" for office rather than "standing" for office in the UK. The politically uncommitted and centrists could consider adopting a stronger political stance for their health. This may also reduce their sitting time, particularly if they shift their views to the right.

\section{Limitations}

A limitation of this research is that all data were from a self report survey and are therefore subject to social desirability and recall biases. The associations are also cross sectional and therefore lack any plausible biopolitical explanatory mechanism. The generalisability of our results is constrained by the high percentage of missing data. To explore these relations further, we investigated the heterogeneity of associations between political affiliation, physical activity, and sitting time across countries, and the patterns of association were similar (data not shown). Finally, data on other facets of the armchair socialist concept were lacking - for example, limited information on alcohol in the Eurobarometer survey prevented us from assessing the potential harms of excesses of chardonnay or champagne among socialists (or reactionaries) and we could not assess preferences for limousine travel rather than more active modes of transportation. This precluded testing of the validity of the constructs of chardonnay or limousine socialists. Further research is needed to validate these potential harms associated with socialism, which could potentially offset the health gains that might be achieved through increased physical activity and reduced sitting time.

\section{Conclusion}

This study refutes the notion that left leaning armchair socialists sit more and move less. It is the politically centrist majority who are more likely to be physically inactive. So called armchair socialists move more than the centrists, as do their right wing counterparts, who also spend less time sitting. Health gains, 
through increased physical activity may result from encouraging centrists and the politically uncommitted to consider moving "off the fence" in either political direction.

Eurobarometer data were provided by the GESIS Social Science Data archive at the Leibniz Institute for the Social Sciences, Germany.

Contributorship: AB conceptualised the study. JG undertook the statistical analysis. KM assisted in drafting the manuscript. All authors contributed to all drafts and approved the final manuscript. $A B$ is the guarantor.

Competing interests: All authors have completed the ICMJE uniform disclosure form at www.icmje.org/coi_disclosure.pdf and declare: no support from any organisation for the submitted work; no financial relationships with any organisations that might have an interest in the submitted work in the previous three years; no other relationships or activities that could appear to have influenced the submitted work. However, all authors declare that they are not politically centrist.

Transparency: The lead author affirms that this is an honest, accurate, and transparent account of the study being reported; that no important aspects of the study have been omitted; and that any discrepancies from the study as planned have been explained. However, the research question posed was developed specifically for The BMJ Christmas issue, and was not intended to imply epidemiologically credible health risks of political centrism.
1 Streeck W, Yamamura K. The origins of nonliberal capitalism: Germany and Japan in comparison. Cornell University Press; 2001

2 Physical Activity Guidelines Advisory Committee. Physical activity guidelines advisory committee report 2008. US Department of Health and Human Services, 2008.

3 Wilmot EG, Edwardson CL, Achana FA, Davies MJ, Gorley T, Gray LJ, et al. Sedentary time in adults and the association with diabetes, cardiovascular disease and death: Systematic review and meta-analysis. Diabetologia 2012;55:2895-905.

4 Papacostas A. Eurobarometer 64.3: foreign languages, biotechnology, organized crime, and health items, November-December 2005. Inter-University Consortium for Political and health items, November

5 Craig CL, Marshall AL, Sjöström M, Bauman A, Booth ML, Ainsworth BE, et al. International Physical Activity Questionnaire (IPAQ): 12-country reliability and validity. Med Sci Sports Exerc 2003;35:1381-95.

6 Rosenberg D, Bull F, Marshall A, Sallis J, Bauman A. Assessment of sedentary behavior with the International Physical Activity Questionnaire. J Phys Activity Health 2008:5(suppl 1):S30-44.

7 World Health Organization. Global recommendations on physical activity for health. WHO, 2010.

8 Bauman AE, Chau J, Ding D, Bennie J. Too much sitting and cardio-metabolic risk: an update of epidemiological evidence. Curr Cardiovasc Risk Rep 2013;7:293-8.

Accepted: 12 November 2014

\section{Cite this as: BMJ 2014;349:g7073}

This is an Open Access article distributed in accordance with the Creative Commons Attribution Non Commercial (CC BY-NC 4.0) license, which permits others to distribute, remix, adapt, build upon this work non-commercially, and license their derivative works on different terms, provided the original work is properly cited and the use is non-commercial. See: http://creativecommons.org/licenses/by-nc/4.0/. 


\section{What is already known}

- A substantial proportion of the population is insufficiently active and spends large amounts of time sitting

- Insufficient physical activity and prolonged sitting time are associated with increased risk of morbidity and mortality related to non-communicable diseases

- Physical activity and sedentary behaviour have many internal (such as attitudes and motivation) and external (social and environmental) influences

\section{What this paper adds}

- People who report extreme left or right political views are more physically active than those who report centrist views

- The term armchair socialist seems to be a misnomer

\section{Table}

\section{Table 1| Physical activity and sitting time by political affiliation among 29193 European adults ${ }^{*}$}

\begin{tabular}{|c|c|c|c|c|}
\hline \multirow[b]{2}{*}{ Outcome, political group } & \multirow{2}{*}{$\begin{array}{l}\text { Significance of difference among } \\
\text { groups ( } F, 3 d f ; P \text { value) }\end{array}$} & \multirow[b]{2}{*}{ Adjusted mean $(95 \% \mathrm{Cl})$ activity (min/week) } & \multicolumn{2}{|c|}{ Adjusted difference from centrist group } \\
\hline & & & Mean $(95 \% \mathrm{Cl})$ & $P$ value $\dagger$ \\
\hline Vigorous activity & $6.07 ; 0.0004$ & & & \\
\hline Left & & $254.8(237.5$ to 272.1$)$ & 29.6 (11.5 to 47.7$)$ & 0.001 \\
\hline Right & & $252.9(235.1$ to 270.6$)$ & 27.7 (9.1 to 46.3$)$ & 0.004 \\
\hline Unknown‡ & & 224.7 (214.9 to 234.6$)$ & $-0.5(-11.8$ to 10.9$)$ & 0.938 \\
\hline Centre & & 225.2 (218.7 to 231.6$)$ & - & - \\
\hline Moderate activity & $1.90 ; 0.128$ & & & \\
\hline Left & & 320.6 (300.9 to 340.3$)$ & $-1.7(-22.3$ to 18.9$)$ & 0.87 \\
\hline Right & & 341.1 (320.9 to 361.3$)$ & $18.9(-2.3$ to 40.0$)$ & 0.08 \\
\hline Unknown‡ & & $313.9(302.7$ to 325.2$)$ & $-8.3(-21.22$ to 4.6$)$ & 0.209 \\
\hline Centre & & $322.2(314.9$ to 329.6$)$ & - & - \\
\hline Walking & $9.31 ;<0.0001$ & & & \\
\hline Left & & 345.9 (329.1 to 362.7$)$ & 34.8 (17.3 to 52.4$)$ & $<0.0001$ \\
\hline Right & & 337.0 (319.8 to 354.2$)$ & 25.9 (7.9 to 43.9$)$ & 0.005 \\
\hline Unknown‡ & & $303.0(293.5$ to 312.6$)$ & $-8.0(-19.0$ to 2.9$)$ & 0.151 \\
\hline Centre & & 311.1 (304.8 to 317.3$)$ & - & - \\
\hline Total activity & $12.86 ;<0.0001$ & & & \\
\hline Left & & 879.6 (844.0 to 915.3$)$ & 57.8 (20.6 to 95.1$)$ & 0.002 \\
\hline Right & & 884.0 (847.4 to 920.6$)$ & 62.2 (23.9 to 100.5$)$ & 0.001 \\
\hline Unknownł & & 781.3 (761.3 to 801.7$)$ & $-40.3(-63.5$ to -17.1$)$ & 0.001 \\
\hline Centre & & 821.8 (808.4 to 835.2 ) & - & - \\
\hline Sitting time (min/ day) & $11.24 ;<0.0001$ & & & \\
\hline Left & & 306.7 (298.4 to 315.1$)$ & $-3.98(-12.7$ to 4.7$)$ & 0.371 \\
\hline Right & & 297.9 (289.3 to 306.5$)$ & $-12.8(-21.9$ to -3.8$)$ & 0.005 \\
\hline Unknown‡ & & 295.2 (290.4 to 300.0$)$ & $-15.5(-21.0$ to -7.0$)$ & 0.000 \\
\hline Centre & & 310.7 (307.6 to 313.8$)$ & - & - \\
\hline
\end{tabular}

${ }^{*}$ Controlling for country, education level, age group, and sex.

tt test. $\mathrm{H}_{0}$ : No difference between the adjusted means.

fUnknown category: political affiliation not known or not stated. 